\title{
Congenitally missing teeth and labio-palatal clefts: keep to the left
}

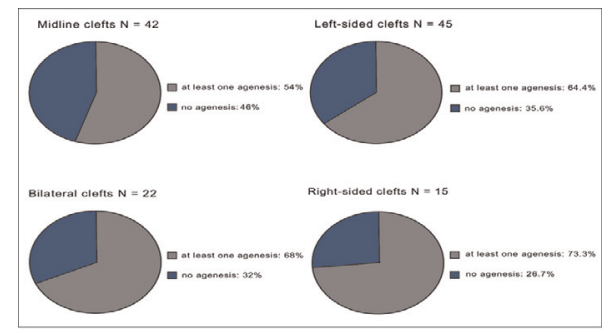

\section{Olivier MATERN, Erik-André SAULEAU, Pascal TSCHILL, Bruno GROLLEMUND, Fabienne PERRIN-SCHMITT}

\section{SUMMARY}

Objectives: dental anomalies are more frequent for individuals with clefts than for the general population. Our objective is to evaluate the prevalence of dental ageneses in a sampling from Alsace made up of 124 children with clefts 181 boys and 43 girls, average age 12.5 years old).

Method: clinical and radiographic exams make it possible to specify the dental formula as well as the type of clefts that are divided into 4 groups: simple Labial Clefts (LC-12.9\%), Labio-Alveolar Clefts (LAC - 4\%), Labio-Palatal Clefts (LPC - 49.2\%) and Palatal Clefts (PC - 33.9\%).

Results: $63 \%$ of the patients present one or more ageneses mainly involving the maxillary lateral incisors (54\%) and the maxillary or mandibular second premolars (32\%). The percentage of children with congenitally missing teeth is, in ascending order, minimal in the case of LC (33\%), average in the case of PC (54\%) and highest in cases of LPC (79\%). The frequency of ageneses increases proportionally with the severity of the cleft. The left side is most affected $(p<0.01)$ regardless of the side of the cleft.

Conclusions: dental ageneses are more frequent on the left side, regardless of the side of the cleft. The greater prevalence on the left side could suggest the intervention of overlapping etiopathogenic factors when clefts and dental ageneses are involved.

\section{KEY WORDS}

Dental ageneses,

Labio-palatal clefts,

Clefts in oral cavity,

Prevalence.
This study was financed by the University Hospital Center of Strasbourg, the Regional Council of Alsace, the French Orthopedic Dento-Facial Society, Pierre Fabre Oral Care, the University of Strasbourg, I'INSERM and the CNRS. 


\section{1 - INTRODUCTION}

Oro-facial clefts are congenital anomalies that occur with an incidence rate comparable to that of Down's Syndrome, namely 1/700 births and as high as 1/300 in populations of South America or South Asia ${ }^{17,20}$.

Their clinical classification makes it possible to distinguish the Palatal Cleft (PC: OMIM* 119540) from the Labio-Alveolar Cleft with or without Palatal lesion (LAC/P: OMIM 119530). LAC/P represents 70 to $80 \%$ of nonsyndromic cases. Presently, it is generally accepted that these nonsydromic LC/PC/LPC are plurifactorial, linking genetic and exogenous factors, without any one single factor prevailing 5, 16,27,28.

\section{2 - METHOD}

The criteria for inclusion in this study were based on the diagnosis of a non-syndromic orofacial cleft in a population of patients with LC/PC/ LPC, drawn on one hand from the orthopedic dento-facial and buccaldental surgery Medical Center of Strasbourg and on the other hand from the multidisciplinary consultation group of the Center of Excellence for labio-palatal clefts of Strasbourg.

Clinical and radiographic exams allowed us to gather three types of data. The analysis of a panoramic view either directly or indirectly (picture of the view) illustrates the dental formula. In cases of a missing tooth, the therapeutic origin must be rejected. The third molars are excluded. A clinical examination makes it possible
The frequency of dental ageneses is higher in patients with LC/PC/LPC than in the general population: $77 \%$ out of 278 patients $^{22}, 67.6 \%$ out of 179 patients ${ }^{1}, 47.5 \%$ out of 120 patients $^{23}$; moreover, this frequency varies from 3.2 to 5.5 in males and from 4.6 to 7.6 in females in control populations ${ }^{19}$. However, this prevalence is variable according to the type of tooth, the placement (upper or lower jaw, the afflicted side or not), the type of cleft and the sex of the patient.

The goal of this study is to evaluate the type and number of ageneses in a sampling of patients with LC/PC/LPC, and to investigate a possible association between these two pathologies.

to report the type of cleft (classification LC, LAC, LPC, PC) and the existence of a syndromic context or not (S, NS). Finally, the contact information of the treating practitioner, and the age and sex of the patient are documented. The clinical data are compared to the information collected in the medical record of the patient.

\section{Statistical analyses}

The aggregate statistical analyses were done at the Public Department of Health of H.U.S., using $R$ software for statistical computing ( $R$ Development Core Team-2010). For the continuous variables, a summary of the shape distribution of values aligned to 
show the average, standard deviation and mean. For qualitative variables, the categorical outcome is the percentage of each modality over the aggregate of registered clefts for which the

\section{3 - RESULTS}

The data from 157 patients, or from their legal guardians, who had signed consent forms, was collected. Among these patients, 33 were excluded from the study either because (their radiographic view was unusable or because they were too young $<5$ years old). Therefore, our study dealt with 124 patients with LC/PC/LPC $(\mathrm{M}=81$ and $\mathrm{F}=43$; NS 109 and $\mathrm{S}=$ 15; average age 12.5 years old.

\section{3 - 1 - Prevalence of LC/PC/LPC}

In our sampling, there are significantly more boys $(65.3 \%)$ than girls $(p<0.001)$ with clefts.

In decreasing order of frequency, LPC appeared most often $(49.2 \%$ of the cases), then PC (33.1\%) and finally LC $(12.1 \%)$. The left side $(36.3 \%)$ is afflicted three times more often than the right side $(12.1 \%)$, and generally speaking, the left side is usually where the affliction is most significant $(p<0.001)$.

\section{3 - 2 - Prevalence of dental ageneses}

The overall prevalence (maxillary and mandibular) of dental ageneses found in our sampling is $63 \%$.

*OMIM: Online Mendelian Inheritance in Man variable is set. An exact binomial test was used to compare the observed percentages. In order to compare the number of respective clefts to one another, a chi-square test ${ }^{2}$ was used.

As for the upper jaw, 14\% of patients have at least one congenitally absent tooth; missing second premolars are most common $151 \%$ of ageneses) (Fig. 1). However, on the lower jaw, the absence of the lateral incisors represents $59.9 \%$ of ageneses and $13 \%$ of the missing teeth are second premolars. Among the participants in our study, we compared the number of ageneses on the upper jaw and lower jaw, and found a 3 to 1 ratio, for every 3 missing maxillary teeth there was one missing tooth on the mandible.

The prevalence of stunted teeth and supernumerary teeth is respectively 12 and $10 \%$ in our sampling.

\section{3 - 3 - Dental ageneses and type of cleft}

In our cohort, patients with LPC are the most affected by dental ageneses (78.7 of the cases). The frequency of dental ageneses clearly increases with the severity of the cleft and the involvement of the secondary palate.

Ageneses present most often on the lower jaw regardless of the type of cleft. Surprisingly, the ratio between maxillary/mandibular involvement changes from $3 / 1$ to $5 / 4$ when there is a PC. In other words, we find 3 missing teeth from the upper jaw versus one tooth from the lower jaw 


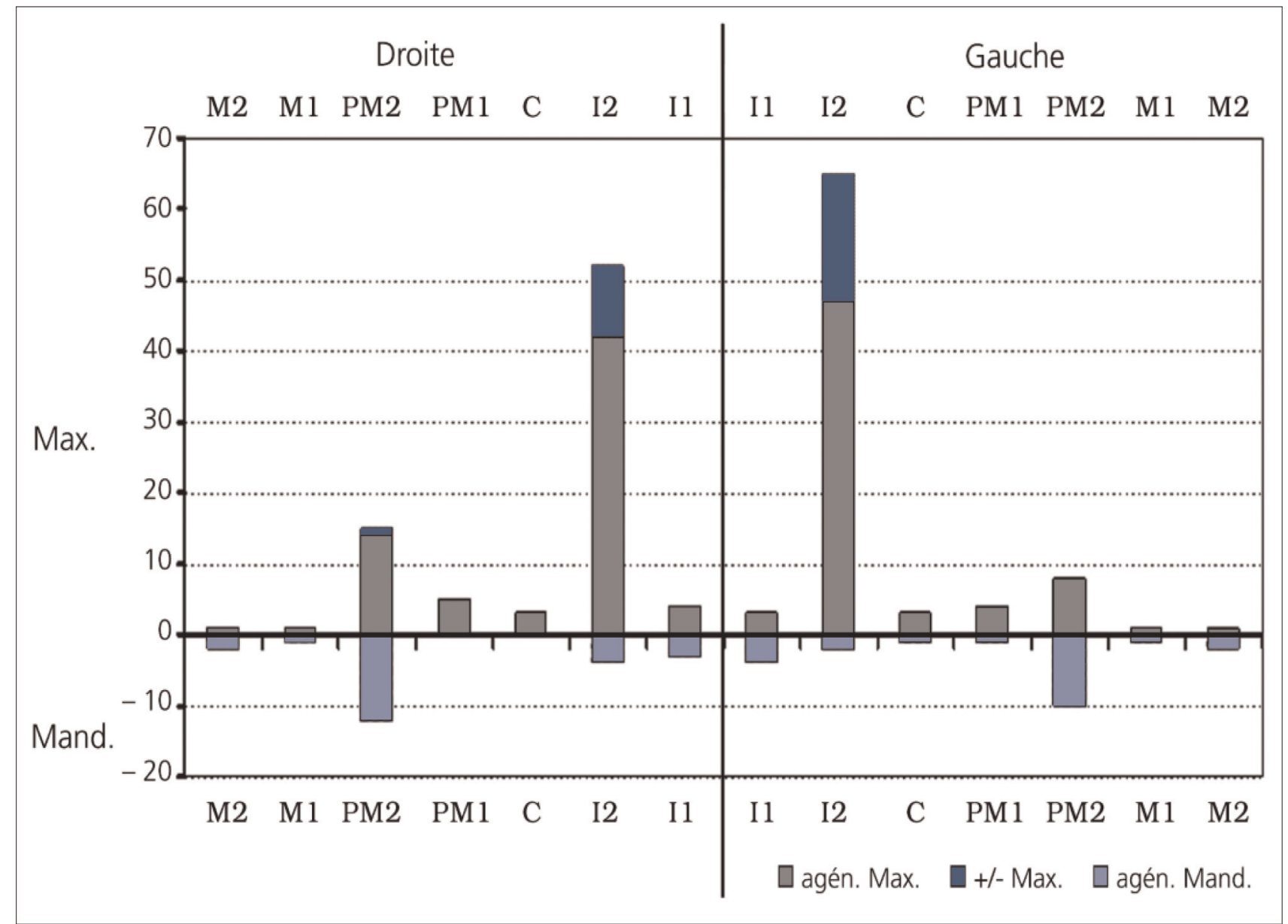

Figure 1

Schematic representation of the number and location of the ageneses / dental anomalies presented by the participants in our study group as a whole.

For each type of tooth, the number of ageneses and anomalies (supplemental, supernumerary or abnormally shaped teeth) on the upper jaw is represented by the dark gray and dark blue columns rising respectively above the 0 (zero) line.

For the mandible, the descending light blue columns represent the number of missing teeth: there are no other dental anomalies on the mandible.

M1-M2: first and second molars;

PM1-PM2: first and second premolars;

C: canine;

11 - 12: central and lateral incisors, respectively;

Agen. Max.: number of ageneses on the maxillary jaw;

+/- Max.: other dental anomalies on the maxillary jaw;

Agen. Mand.: number of ageneses on the mandible. 
in cases of LC, LAC and LPC; 5 missing maxillary teeth for every 4 missing mandibular teeth in the case of $\mathrm{CP}$

\section{3-4-Dental ageneses and side of the cleft}

Among the 124 patients, a distinction must be made between lateralized clefts $(N=60)$ and midline facial clefts (PC) along with bilateral clefts (LC/LPC) $(N=64)$.
Among the 64 cases of midline or bilateral clefts, 30 are combined with ageneses on the right and 28 on the left (certain cases present ageneses on both sides).

However, among the 60 patients who have right-sided clefts $(N=15)$ or left-sided clefts ( $N=45), 20$ have no agenesis, 24 have at least one unilateral or contralateral agenesis with their cleft and 16 have bilateral ageneses (Fig. 2).

In all, considering that each missing tooth is an independent occurrence

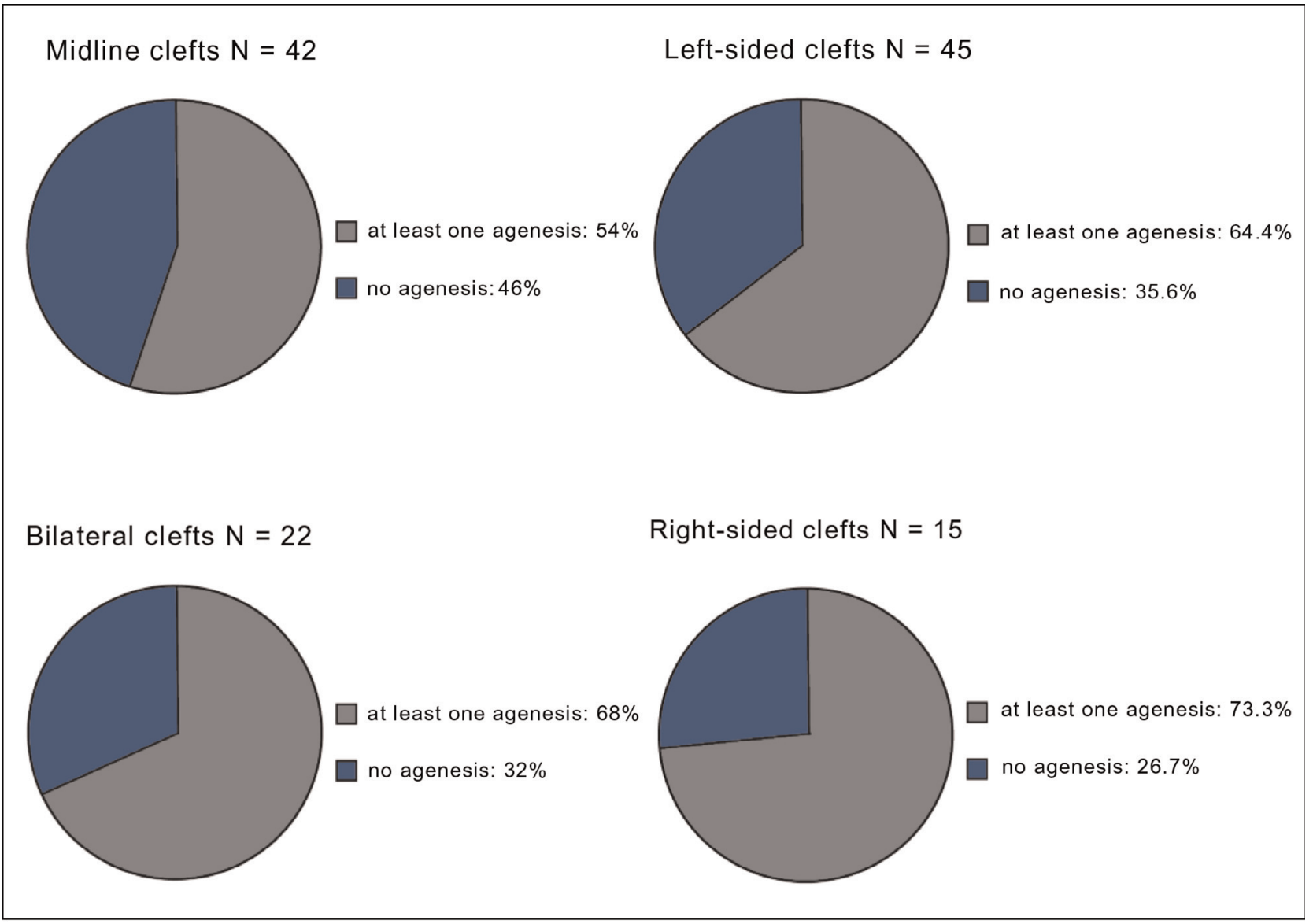

Figure 2

Frequency of dental ageneses based on the type of cleft.

Classification by ascending order, from the top left to the bottom right, of the frequency of dental ageneses in patients presenting respectively a midline, left-sided, bilateral et right-sided cleft. 
and not necessarily symmetrical, the figures show 56 cases of ageneses of at least one tooth $(24$ unilateral $+2 \times$ 16 bilateral). It seems that in $58.5 \%$ of the cases, left-sided clefts are correlated to left-sided ageneses, and that $66.7 \%$ of right-sided clefts are linked to left-sided ageneses. The chi-square test shows that these numbers significantly differ $(p<0.01)$.

In conclusion, right-sided clefts are more often correlated with contralateral ageneses than left-sided clefts.

\section{3-5 - Ageneses are significantly more frequent on the left side}

Because:

- there are more left-sided (73\%) than right-sided $(27 \%)$ clefts, if we leave out bilateral and midline clefts $(p<0.01)$;

- significantly, $66.7 \%$ of right-sided clefts are linked to contralateral ageneses as opposed to only $41.5 \%$ of left-sided clefts ( $p<$ 0.01);

- but bilateral and midline clefts are not linked to more ageneses on either side.

this prevalence for clefts on the left side is even greater for girls.

We note that a prevalence of $63 \%$ for dental ageneses in our sampling of patients with clefts. These results, clearly greater than the prevalence of dental ageneses in the normal population, correspond to higher proportions found in the literature $\left(77 \%{ }^{22}\right.$ and $\left.67.6 \%{ }^{1}\right)$.

When we cross the variables "dental anomalies" and "type of cleft", we see an increase in the frequency of dental ageneses with the involvement of the secondary palate that agrees with the findings of other studies $^{2,4,9,10,12,25}$. Surprisingly, we see a marked increase in the number of ageneses on the mandible in cases of isolated cleft palate.

By crossing the variables "cleft side" and "ageneses side", we logically
Our study confirms that the left is the side most afflicted with clefts, and 
expect that the ageneses would be more frequent on the side of cleft. That is the case for left-sided clefts. Given that left-sided clefts are more frequent, the findings of most studies indicate that dental ageneses are more frequent on the left side ${ }^{1,22}$. We confirm these findings in our study and support them in an original way with data showing that in cases of right-sided clefts, leftsided contralateral ageneses are significantly more frequent.

Determining the right-left symmetry in the course of development is a complex subject, given that the molecular data are still incomplete: the laterality of the cephalic region appears to be established independently from that of the body ${ }^{14}$. In addition, the experimental results that establish that signaling by FGF8 and Shh respectively determines the right and left sides of the chicken embryo leads to the opposite conclusion in mice ${ }^{15}$. Nonetheless, it is clear that in all chordates, whatever the initial signaling during early development, the left side is actively determined by the specific expression of a series of three pivotal genes (Nodal $\rightarrow$ Lefty 1 and $2 \rightarrow$ Pitx2) whose expression is repressed on the right side ${ }^{3}$.

Therefore, we suggest that rightsided clefts might be the rudimentary form of bilateral clefts: the prevalence of left-sided clefts reflects the dominant influence of the left side in

\section{5 - CONCLUSION}

This study which was conducted in France and which associates dental anomalies with LC/LPC/PC makes it possible to confirm our hypotheses: determining lateralization and it might be that the left-sided clefts are linked to dysfunctions that reduce left signaling. Bilateral clefts originate perhaps from gene disorders not linked to laterality and right-sided clefts might be linked to defective genes insufficiently repressed from the right side. Therefore, mice embryos with homozygous mutants of lefty- 1 have an abnormal bilateral expression with molecular markers normally expressed uniquely on the left, such as nodal $^{13}$.

Given the greater prevalence of dental ageneses in our sampling of patients with clefts $(63 \%)$, the existence of a common etiopathogeny seems obvious to us. Since a portion of the number of dental ageneses increases with the severity of the affliction (i.e. when the secondary palate is involved), and in addition there is an increase in the number of ageneses on the mandible in cases of isolated cleft palate, we can perhaps incriminate pathway signaling specifically implicated in the formation of the secondary palate, that intervenes at a later moment in embryological time (the primary palate forms between the $4^{\text {th }}$ and $6^{\text {th }}$ week in utero, the secondary palate between the $6^{\text {th }}$ and $9^{\text {th }}$ week). Moreover, Mxs1 and Pax9 deficient mice exhibit anomalies that affect simultaneously the palate and the teeth $7,11,16,18,21,26$.

dental anomalies of number and form are more frequent in patients with clefts. 
This frequency, which is greater than in the general population, firmly links these two pathologies and can only lead us to conclude that there is an overlapping etiopathogeny.

We can perhaps even consider the isolated presence of dental agenesis or of supplemental/supernumerary teeth to be a rudimentary form of cleft, and consequently consider these dental anomalies to be destabilizing factors putting these patients at risk ${ }^{8}$.

In this context, it might be important to study panoramic views of the ascendants and descendants of patients with a cleft in order to confirm the role of heredity, of genetic versus environmental factors in the appearance of these malformations.

\section{REFERENCES}

1. Aizenbud D, Camasuvi S, Peled M, Brin I. Congenitally missing teeth in the Israeli cleft population. Cleft Palate Craniofac J 2004;42 (3):314-7.

2. Bartzela TN, Carels CE, Bronkhorst EM, Rønning E, Rizell S, Kuijpers-Jagtman AM. Tooth agenesis patterns in bilateral cleft lip and palate. Eur J Oral Sci 2010;118(1):47-52.

3. Boorman CJ, Shimeld SM. The evolution of left-right asymmetry in chordates. Bioessays 2002; 24(11):1004-11.

4. Dewinter G, Quirynen M, Heidbüchel K, Verdonck A, Willems G, Carels C. Dental abnormalities, bone graft quality, and periodontal conditions in patients with unilateral cleft lip and palate at different phases of orthodontic treatment. Cleft Palate Craniofac J 2003;40(4): 343-50.

5. Graber TM, Vanarsdall RL, Vig KWL. Orthodontics: current principles and techniques. $4^{\text {th }}$ ed. St Louis; Elsevier Mosby 2005;109-10.

6. Kim NY, Baek SH. Cleft sidedness and congenitally missing or malformed permanent maxillary lateral incisors in Korean patients with unilateral cleft lip and alveolus or unilateral cleft lip and palate. Am J Orthod and Dentofac Orthop 2006;130(6):752-8.

7. Kist R, Greally E, Peters H. Derivation of a mouse model for conditional inactivation of Pax9. Genesis 2007;45(7):460-7.

8. Küchler EC, da Motta LG, Vieira AR, Granjeiro JM. Side of dental anomalies and taurodontism as potential clinical markers for cleft subphenotypes. Cleft Palate Craniofac J 2011;48(1):103-8.

9. Larson M, Hellquist R, Jakobsson OP. Classification, recording, and cleft palate surgery at the Uppsala Cleft Palate Center. Scand J Plast Reconstr Surg Hand Surg 1998;32(2):185-92.

10. Letra A, Menezes R, Granjeiro JM, Vieira A. Defining subphenotypes for oral clefts based on dental development. J Dent Res 2007;86(10):986-91.

11. Lidral AC, Reising BC. The role of MSX1 in human tooth agenesis. J Dent Res 2002;81(4):274-8.

12. Menezes R, Vieira A. Dental anomalies as part of the cleft spectrum. Cleft Palate Craniofac J 2008;45(4):414-9.

13. Meno C, Shimono A, Saijoh Y, Yashiro K, Mochida K, Ohishi S, Noji S, Kondoh H, Hamada H. Lefty-1 is required for left-right determination as a regulator of lefty-2 and nodal. Cell 1998;94(3):287-97.

14. Mercola M, Levin M. Left-right asymmetry determination in vertebrates. Annu Rev Cell Dev Biol 2001;17:779-805.

15. Meyers EN, Martin GR. Differences in left-right axis pathways in mouse and chick: functions of FGF8 and SHH. Science 1999;285(5426):403-6. 
16. Modesto A, Moreno LM, Krahn K, King S, Lidral AC. Msx1 and orofacial clefting with and without tooth agenesis. J Dent Res 2006;85(6):542-6.

17. Mossey PA, Little J. Addressing the challenges of cleft lip and palate research in India. Indian J Plast Surg 2009;42 (Suppl):S9-S18.

18. Nakatomi M, Wang XP, Key D, Lund JJ, TurbeDoan A, Kist R, Aw A, Chen Y, Maas RL, Peters H. Genetic interactions between Pax9 and Msx1 regulate lip development and several stages of tooth morphogenesis. Dev Biol 2010;340(2):438-49.

19. Polder BJ, Van't Hof MA, Van der Linden FP, KuijpersJagtman AM. A meta-analysis of the prevalence of dental agenesis of permanent teeth. Community Dent Oral Epidemiol 2004; 2(3):217-26.

20. Robert $E$, Källén B, Harris J. The epidemiology of orofacial clefts. 1. Some general epidemiological characteristics. J Craniofac Genet Dev Biol 1996;16(4):234-41.

21. Satokata I, Maas R. Msx 1 deficient mice exhibit cleft palate and abnormalities of craniofacial and tooth development. Nat Genet 1994;6(4):348-56.

22. Shapira Y, Lubit E, Kuftinec MM. Hypodontia in children with various types of clefts. Angle Orthod 2000;70(1):16-21.

23. Slayton RL, Williams L, Murray JC, Wheeler JJ, Lidral AC, Nishimura CJ. Genetic association studies of cleft lip and/or palate with hypodontia outside the cleft region. Cleft Palate Craniofac J 2002; 40(3):274-9.

24. Stanier P, Moore GE. Genetics of cleft lip and palate: syndromic genes contribute to the incidence of non-syndromic clefts. Hum Mol Genet 2004;13 Spec No 1:R73-81.

25. Suzuki A, Watanabe M, Nakano M, Takahama Y. Maxillary lateral incisors of subjects with cleft lip and/or palate: Part 2. Cleft Palate Craniofac J 1992;29(4):380-4.

26. Vastardis H, Karimbux N, Guthua SW, Seidman JG, Seidman CE. A human MSX1 homeodomain missense mutation causes selective tooth agenesis. Nat Genet 1996;13(4):417-21.

27. Vieira AR, Meira R, Modesto A, Murray JC. MSX1, PAX9, and TGFA contribute to tooth agenesis in humans. J Dent Res 2004;83(9):723-7.

28. Vieira AR, Modesto A, Meira R, Barboda AR, Lidral AC, Murray JC. Interferon regulatory factor 6 (IRF6) and fibroblast growth factor receptor 1 (FGFR1) contribute to human tooth agenesis. Am J Med Genet A 2007;143(6):538-45. 